\title{
IMPLEMENTASI JUAL BELI AKAD ISTISHNA' DIKONVEKSI DUTA COLLECTION'S YAYASAN DARUT TAQWA SENGONAGUNG
}

\author{
Moh. Mukhsinin Syu'aibi, Ifdlolul Maghfur \\ mukhsinin.2000@gmail.com, ifdholulmaghfur@yudharta.ac.id \\ Universitas Yudharta Pasuruan
}

\begin{abstract}
Buying and selling istishna', namely buying and selling by order, in fiqh is often referred to as buying and selling goods whose goods do not yet exist or are still in process. Buying and selling clothes at the Duta Collection's Foundation, Darut Taqwa Sengonagung Foundation is done by order (istishna'). Buying and selling transactions certainly involve two or more people to carry out the transaction, it is possible that one of the parties has committed a violation or not.

The problem in this research is how to resolve it when there is a mismatch of goods that have become ready in the practice of istishna contract 'at the Ambassador Collection of Darut Taqwa Sengonagung Foundation. This type of research method used is qualitative research field (field research) that is descriptive analytic. Data collection techniques were carried out with documentation and interviews with several people, resource persons, 4 speakers from the makers or employees of convection and 2 speakers from the customer. The results in this study indicate that: First, the practice of buying and selling clothing at Duta Collection's already has ways to resolve when material errors occur the convection lowers the selling price to the customer. Secondly, in the analysis of Islamic law, Duta Collection's convection is in accordance with sharia law meaning that when there is an error from the convection party and the consumer feels that it is not according to the order it has been agreed that there is a price reduction or the goods will be replaced with the order.
\end{abstract}

Keywords: Convection, Istishna ', Islamic law 


\section{PENDAHULUAN}

Perikatan atau perjanjian dalam kontek fikih muamalah sering kali di sebut juga dengan akad. Kata akad berasal dari bahasa Arab al- 'aqd bentuk jamaknya al-'uqud yang mempunyai arti mengikat, sambungan,dan janji. ${ }^{1}$ Perjanjian (akad) mempunyai arti penting dalam kehidupan masyarakat. Akad merupakan dasar dari sekian banyak aktivitas keseharian kita. Melalui akad seorang lelaki disatukan dengan seorang wanita dalamsuatu kehidupan bersama, dan melalui akad juga berbagai kegiatan perdangandan usaha kita dapat dijalankan.Jual beli merupakan aktifitas muslim yang diperkenankan Allah. Dan merupakan sunatullah yang telah berjalan turun-temurun. Jual beli memiliki bentuk yang bermacam-macam biasanya dilihat dari cara pembayaran, akad, penyerahan barang dan barang yang diperjual belikan. Islam sangat memperhatikan unsur ini dalam transaksi jual beli. ${ }^{2}$

Bentuk-bentuk akad jual beli yang telah dibahas para ulama dalam fiqih muamalah terbilang sangat banyak.Jumlahnya bisa mencapai belasan bahkan sampai puluhan.Sungguhpun demikian, Untuk memenuhi kebutuhan hidupnya, manusia selalu berinteraksi dengan sesamanya guna mengadakan berbagai transaksi ekonomi. Salah satunya adalah jual-beli yang melibatkan dua pelaku, yaitu penjual dan pembeli. Biasanya penjual adalah produsen sedangkan pembeli adalah konsumen. Pada kenyataannya konsumen kadang memerlukan barang yang tidak atau belum dihasilkan oleh produsen sehingga konsumen melakukan transaksi jual-beli dengan produsen melalui cara pesanan (Istishna').

Masyarakat Indonesia khusunya banyak sekali yang berprofesi sebagai pedagang. Jual beli diatur juga dalam syariah islam. Fenomena jual beli di masyarakat sudah mulai keluar dari syariat islam. Jual beli terdiri dari 2 macam, yaitu jual beli tunai dan jual beli secara tangguh.Jual beli secara tangguh pun terbagi lagi menjadi jual beli murabahah, salam dan istishna'.Jual beli Salam adalah pembelian barang yang diserahkan dikemudian hari, sedangkan pembayaran dilakukan dimuka.,

Sehubungan dengan itu, akad yang merupakan bentuk perikatan dalam Islam memiliki kepentingan besar untuk menyorot diterima atau ditolaknya suatu transaksi.Pada dasarnya, akad merupakan bentuk perbuatan yang dibolehkan (aljawaz wal ibahah) atau bebas tanpa ikatan.Karena itu

\footnotetext{
${ }^{1}$ Qamarul Huda, Fiqih Mu'amalah, (Yogyakarta : Teras. 2011), Hal.25.

${ }^{2}$ Rachmat Syafei, Fiqih Mu'amalah, (Bandung: CV. Pustaka Setia. 2001), Hal.15
} 
kebebasan berakad tergantung kepada bentuk yang dibenarkan syariat. ${ }^{3}$ Kebebasan akad dalam makna ini menyatakan bahwa setiap bentuk akad dipandang bebas untuk dilakukan selamarukun dan persyaratan untuk melakukannya telah terwujud.Artinya akad yang dilakukan dengan adanya unsur pemaksaan menjadi batal atau tidak sah. ${ }^{4}$

Duta Collection's adalah salah satu unit usaha konveksi yang ada di Yayasan Darut Taqwa Sengonagung.Berdiri sejak tahun 2013 konveksi ini sudah melayani ribuan potong baju kepada konsumen.Pada jurnal ini akan dibahas tentangbagaimana pihak konveksi ini menerapkan atau mengimplementasikan akad salam dalam melayani konsumen.

\section{PENGERTIAN ISTISHNA'}

Menurut Ichtiar Bara Van Hoeve, istishna' adalah (mintadibuatkan/ditempat) akad yang mengandung tuntutan agar shani'membuat suatu pesanan dengan ciri-ciri khusus dan harga tertentu. ${ }^{5}$

Menurut Drs. Ghufron A. Mas'adi, M.Ag, istishna' adalah akaddengan pihak pengrajin atau pekerja untuk mengerjakan suatu produkbarang (pesanan) tertentu dimana materi dan biaya produksi menjaditanggung jawab pihak pengrajin. ${ }^{6}$

Menurut Muhammad Syafi'i Antonio, istishna' adalah transaksi bai'istishna' merupakan kontrak penjual antara pembelian dan pembuatbarang, dalam kontrak ini, pembuat barang menerima pesanan daripembeli. Pembuat barang lalu berusaha melalui orang lain untukmembuat atau membeli barang menurut spesifikasi yang telah di sepakatidan menjualnya kepada pembeli akhir. Kedua belah pihak bersepakatatas harga serta sistem pembayaran, apakah pembayaran dilakukan

dimuka melalui cicilan, atau ditangguhkan sampai suatu waktu padamasa yang akan datang. ${ }^{7}$

Menurut Zuhaily, bai'istishna' adalah akad bersama produsen untuksesuatu perkerjaan tertentu atau jual beli suatu barang yang akan

\footnotetext{
${ }^{3}$ Abdul Hamid Mahmud Al-Baeeali, Dawabit al-,, Uqud (Kairo: Maktabah Wahbah, TT), h. 247.

${ }^{4}$ Nasrun Haroen, Fiqh Muamalah (Jakarta: Gaya Media Pratama, 2007), h. 106.

${ }^{5}$ Abdul Aziz Dahlan, Ensiklopedi Hukum Islam, (Jakarta: PT. Ictiar Baru Van Hoeve), hlm. 779

${ }^{6}$ Ghufron. A. Mas'adi, Fiqih Muamalah Kontektual, (Jakarta: PT Raja Grafindo Persada, 2002),hlm. 144

${ }^{7}$ Muhammad Syafi'i Antonio, Bank Syari'ah, (Jakarta; Gema Insani Press, 2001),hlm. 113
} 
dibuatoleh produsen yang juga menyediakan barang bakunya, sedangkan jikabarang bakunya dari pemesan maka akan menjadi akad ijarah (sewa),pemesan hanya menyewa jasa produsen untuk membuat barang.Selanjutnya, Zuhaily, mengemukakan bahwa istishna' menyerupai akadsalam, karena termasuk bai' ma'dum (jual beli barang tidak ada), jugakerena barang yang di buat melekat pada waktu akad pada tanggunganpembuat (shani') atau penjual. ${ }^{8}$

Menurut Fatwa DSN No. 06/DSN MUI/IV/2000 tentang jual beliistishna', bai' istishna' merupakan kontrak penjualan antara mustasni'(pembeli) dan sani' (suplier) dimana pihak suplier menerima pesanandari pembeli menurut spesifikasi tertentu. Pihak suplier berusaha melaluiorang lain untuk membeli atau membuat barang dan menyampaikannyakepada pemesan. Pembayaran dapat dilakukan di muka, cicilan atauditangguhkan hingga waktu tertentu. ${ }^{9}$

Pada dasarnya, bai' istishna' merupakan transaksi jual beli cicilanpula seperti transaksi murabahah muajjal.Namun, berbeda dengan jualbeli murabahah dimana barang diserahkan di muka, sedangkan uangnyadibayar cicilan, dalam jual beli istishna' barang diserahkan dibelakang,walaupun uangnya juga sama-sama dibayar secara cicilan. ${ }^{10}$

\section{RUKUN DAN SYARAT ISTISHNA'}

Rukun dari akad Istishna' yang harus dipenuhi dalam transaksi ada beberapa hal, yaitu :

1. Pelaku akad, mustasni' (pembeli) adalah pihak uyang membutuhkan dan memesan barang, dan shani' (penjual) adalah pihak yang memproduksi barang pesanan.

2. Objek akad, yaitu barang atau jasa (mashnu') dengan spesifikasinya dan harga (tsaman), dan

3. Shighah, yaitu ijab dan qobul. ${ }^{11}$

Di samping segenap rukun harus terpenuhi, ba'i istishna' juga mengharuskan tercukupinya segenap syarat pada masing-masing rukun. Di

\footnotetext{
8 Ismail Nawawi, Fiqih Muamalah Klasik dan Kontemporer,Bogor ;Ghalia Indonesia,2012,cet-I hlm. 130

${ }^{9}$ Husaini Mansur Dan Dhani Gunawan, Dimensi Perbankan Dalam Al-Qur'an, (Jakarta: PT. Visi Citah Kreasi, 2007), Cet. I, Hlm. 102

${ }^{10}$ Adiwarman A. Karim, Bank Islam; Analisis Fiqh Dan Keuangan, Eds. 3, (Jakarta: PT. Raja Grafindo persada, 2007), hlm. 126

${ }^{11}$ Ascarya, Akad dan Produk Bank Syariah, (Jakarta:RajawaliPers.2013), hlm 97
} 
bawah ini akan di uraikan di antara dua rukun terpenting, yaitu modal dan barang.

1. Modal transaksi ba'i istishna'

a. Modal harus di ketahui

b. Penerimaan pembayaran salam

2. Al-muslam fiihi (barang)

a. Harus spesifik dan dapat diakui sebagai utang

b. Harus bisa di identifikasi secara jelas

c. Penyerahan barang harus di lakukan di kemudian hari

d. Kebanyakan ulama mensyaratkan penyerahan barang harus di tunda pada suatu waktu kemudian, tetapi madzhab syafi'i

e. Boleh menentukan tanggal waktu di masa yang akan datang untuk penyerahan barang

f. Tempat penyerahanpenggantian muslam fiihi dengan barang lain ${ }^{12}$

\section{DASAR HUKUM ISTISHNA'}

Akad istishna' adalah akad yang halal dan didasarkan secara sayr'i di atas petunjuk Al-Quran, As-Sunnah dan Al-Ijma' di kalangan muslimin. Al-Quran

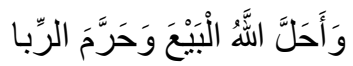

Allah telah menghalalkan jual-beli dan mengharamkan riba.

(Qs. Al Baqarah: 275)

Berdasarkan ayat ini dan lainnya para ulama' menyatakan bahwa hukum asal setiap perniagaan adalah halal, kecuali yang nyata-nyata diharamkan dalam dalil yang kuat dan shahih.

As-Sunnah

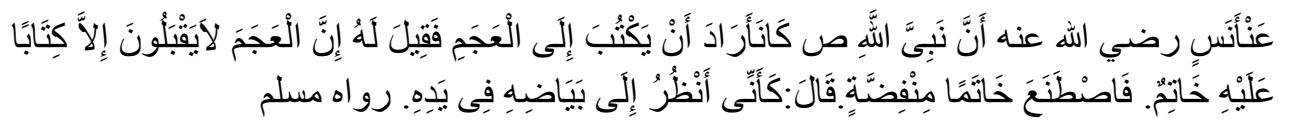

Dari Anas RA bahwa Nabi SAW hendak menuliskan surat kepada raja non-Arab, lalu dikabarkan kepada beliau bahwa raja-raja nonArab tidak sudi menerima surat yang tidak distempel. Maka beliau pun memesan agar ia dibuatkan cincin stempel dari bahan perak.

${ }^{12}$ https://syafaatmuhari.wordpress.com/2011/07/03/ba'i-istishna'/ 
Anas menisahkan: Seakan-akan sekarang ini aku dapat menyaksikan kemilau putih di tangan beliau." (HR. Muslim)

\section{Al-Ijma'}

Sebagian ulama menyatakan bahwa pada dasarnya umat Islam secara de-facto telah bersepakat merajut konsensus (ijma') bahwa akad istishna' adalah akad yang dibenarkan dan telah dijalankan sejak dahulu kala tanpa ada seorang sahabat atau ulamakpun yang mengingkarinya.Dengan demikian, tidak ada alasan untuk melarangnya.

\section{Kaidah Fiqhiyah}

Para ulama di sepanjang masa dan di setiap mazhab fiqih yang ada di tengah umat Islam telah menggariskan kaedah dalam segala hal selain ibadah:

$$
\text { الأصل في الأشياء الإباحة حتى يدل الدليل على التحريم }
$$

Hukum asal dalam segala hal adalah boleh, hingga ada dalil yang menunjukkan akan keharamannya.

\section{Logika}

Orang membutuhkan barang yang spesial dan sesuai dengan bentuk dan kriteria yang dia inginkan. Dan barang dengan ketentuan demikian itu tidak di dapatkan di pasar, sehingga ia merasa perlu untuk memesannya dari para produsen.

\section{METODE PENELITIAN}

Penelitian ini menggunakan penelitian kualitatif dengan Sumber data primer Customer, Manajer Duta Collection's, Karyawan lain yang bertugas konveksi tersebut. Sedangkan sumber data sekunder berasal dari buku-buku maupun literatur lain. Teknik pengumpulan data dilakukan dengan 3 cara yaitu : Observasi, Wawancara dan Dokumentasi.

\section{GAMBARAN UMUM DUTA COLLECTION'S}

Yayasan Darut Taqwa Sengonagung adalah yayasan yang menaungi lembaga mulai dari PAUD sampai dengan Universitas dan banyak pula siswa,setiap tahun siswa/i terus meningkat dari data panitia penerimaan siswa/i baru (PSB) sebelum konveksi didirikan kurang lebih 1.521 siswa/i, 
dan pondok pesantrennya kurang lebih 838 santri, belum lagi siswa/i serta santri lama.

Dari banyaknya siswa/i yang masuk maka banyak pula permintaan dan kebutuhan yang harus disediakan, dalam hal ini pengurus Yayasan Darut Taqwa megambil kebijakan untuk mendirikan unit usaha konveksi. Pada tanggal 27 Agustus 2013 didirikanlah Duta Collection's sebagai unit usaha konveksi Yayasan Darut Taqwa,dan diresmikan pada tangga 10 Oktober 2013.

Kepuasan konsumen adalah prioritas utama sekaligus motivasi kami untuk secara berkelanjutan menghadirkan model atau desain seragam terbaru setiap saat. Sehingga membantu kami untuk menjadi perusahaan konveksi berkualitas di daerah Pasuruan.

\section{MEKANISME PEMESANAN DI DUTA COLLECTION'S}

1. Transaksi di lokasi

Konsumen yang datang umumnya berlokasi tidak jauh dari konveksi dan tidak sedikit yang dating hanya membawa gambar dikertas dan kemudian meminta didesainkan lalu diproduksi sesuai keinginan konsumen, dan ada juga yang melakukan tawar menawar harga untuk dijual kembali dan juga melihat bahan ukuran dan jumplah barang yang akan di pesan . Transaksi dilokasi pemesan memberi uang muka atau DP sebesar $50-75 \%$ dari jumplah pemesanan.Dan batas minim pemesanan yaitu minimal 12 pcs.

2. Transaksi melalui e-mail

Pemesanan ini umumnya dilakukan dengan pelanggan yang telah beberapa kali melakukan transaksi dengan Duta Collection's. File yang dikirim berupa desain siap di produksi, dan pengirim harus menyertakan keterangan untuk bahan, ukuran dan jumlah secara detail, setelah file dikirim oleh konsumen diharuskan konfirmasi sekaligus bernegosiasi perihal harga melalui telepon. ${ }^{13}$

3. Tentukan Jenis Material (kain, kancing, aksesoris, dll) yang ingin Digunakan.

4. Proses Penawaran dan Kesepakatan Harga.

5. Proses Produksi.

\footnotetext{
${ }^{13}$ Hasil Wawancara dengan Karim selaku karyawan desaint pada tanggal 10 September 2019 pukul 15:00
} 
Variabel lead time proses produksi seragam adalah kuantitas,style produk, dan jadwal produksi yang telah atau sedang berjalan.

Tabel: Pemesanan Beberapa Konsumen Duta Collection's

\begin{tabular}{|l|l|l|c|c|c|c|c|c|c|c|}
\hline \multirow{2}{*}{ Pemesan } & \multirow{2}{*}{ Item } & \multirow{2}{*}{$\begin{array}{c}\text { Jenis } \\
\text { kain }\end{array}$} & $\mathbf{S}$ & $\mathbf{M}$ & $\mathbf{L}$ & $\mathbf{X L}$ & $\mathbf{2 X L}$ & & $\begin{array}{c}\text { Jml } \\
\text { Harga } \\
\text { Satuan }\end{array}$ & $\begin{array}{c}\text { Uang } \\
\text { Muka } \\
(\mathbf{R p})\end{array}$ \\
\hline Arrahmad & Baju koko & Tessa & 11 & 20 & 7 & 1 & & 39 & 75,000 & $1,000,000$ \\
\hline Jabung & Almamater & Oxford & 6 & 7 & 5 & 1 & & 19 & 80,000 & 500,000 \\
\hline $\begin{array}{l}\text { MA Darut } \\
\text { Taqwa }\end{array}$ & Wearpack & Nagata & & 5 & 14 & 6 & & 25 & 105,000 & $1,000,000$ \\
\hline Satpam & Rompi & Nagata & & & & 30 & 10 & 40 & 40,000 & 300,000 \\
\hline $\begin{array}{l}\text { MTs. } \\
\text { Lawang }\end{array}$ & Olahraga & TC & 15 & 20 & 19 & 3 & & 54 & 85,000 & $1,300,000$ \\
\hline $\begin{array}{l}\text { SMA } \\
\text { Darut } \\
\text { Taqwa }\end{array}$ & Wearpack & NAGATA & & 15 & 11 & 4 & & 30 & 105,000 & $1,500,000$ \\
\hline
\end{tabular}

\section{PROSES PEMBUATAN PESANAN DI DUTA COLLECTION'S}

Proses pembuatan seragam, kaos, jas, rompi dan lain-lain di Duta Collection's yaitu:

1. Akad (Pemesanan)

Pada tahap ini seorang konsumen akan dilayani oleh petugas recepsionis dan ada proses akad atau kesepakatan yang meliputi jenis kain, model, ukuran, jenis kelamin, jumlah, harga dan waktu pengambilan. Ketika sudah disepakati akan dibuatkan nota.

2. Pembayaran

Setelah terjadi akad antara kedua belah pihak maka konsumen harus membayar uang muka sesuai yang disepakati.

3. Pembuatan Mal (Contoh potongan)

Setelah kedua belah pihak sepakat maka pada tahap ini kain akan di Mal atau digambar guna mempermudah dalam hal pemotongan.

4. Pemotongan Kain

Disini kain akan dipotong dengan mudah karena sudah digambar sesuai dengan proses pada tahap ke tiga sebelumnya. 
5. Mesin Jahit

Setelah dipotong, pada proses ini petugas akan menjahit dengan hati-hati sehingga konsumen akan merasa senang dan sesuai pesanan. Pada proses ini ada Quality Control ( $Q C)$ bagaimana sekiranya produk yang dihasilkan benar-benar sesuai pesanan konsumen dan kualitas terjaga.

6. Mesin Obras

Pada tahap ini, kain yang sudah di jahit akan di obras agar jahitan lebih kuat dan tidak mudah robek.

7. Pengontrolan

Petugas akan mengontrol dari hasil beberapa tahap sebelumnya, jika ada cacat atau kekurangan, maka aka nada evaluasi.

8. Mesin Itik

Pada tahap ini baju akandilubangi dan pemasangan kancing.

9. Finishing

Pada tahap ini

\section{KASUS KOMPALIN}

Pada bulan Februari 2019 ada organisasi Karangtaruna desa Sekarmojo memesan Jas almamater warna biru tua dengan jumlah 15 dan jenis kain yang sesuai disepakati, pihak konveksi memberi harga per almamater Rp. 125.000. konsumen memberi uang muka Rp. 1.500.000 dan telah disepakati antara konsumen (pemesan) dengan pihak konveksi 1.5 bulan barang bisa di ambil.Ketika jatuh tempo pengambilan konsumen ada kompalin bahwasannya warna kain kurang sesuai dengan kesepakatan yakni biru kurang tua.Dari akar masalah ini memang jelas pihak konveksi yang melakukan kesalahan, konsumen merasa kesepakan awal pada saat akad tidak dijalankan pihak konveksi. Dengan demikian atas dasar saling merelakan maka pihak konveksi memberikan solusi potongan harga yang awalnya Rp. $125.000 @$ jas maka dihargai Rp. 115.000 kedua belah pihakpun sepakat. ${ }^{14}$

Kasus kedua yakni pada bulan Agustus 2019, KJKS Arjuna Sengonagung sebagai konsumen yakni memesan seragam kemeja sejumlah 6 dengan warna hijau jenis kain tessa. Singkat cerita pada saat jatuh tempo waktu pengambilan, pihak konsumen mengambil dan dicek ada 2 baju kancing baju tidak sama yakni terlalu kecil ukurannya pihak konsumen

\footnotetext{
${ }^{14}$ Hasil Wawancara dengan Jamal selaku manajer desaint pada tanggal 10 September 2019 pukul 14:00
} 
complain kepada pihak konveksi dan pihak konveksi meminta maaf karena ada kelalaian pada staff bagian QC (quality control) atas dasar itu kedua belah pihak sepakan agar pihak konveksi mengganti dengan kancing yang sesuai dan sama dengan kemeja lainnya.

Dari uraian dan contoh kasus complain diatas bahwa, akad istishna' yang diterapkan pihak Duta Collection's kepada konsumen selalu sesuai ketentuan yang telah disepakati yang meliputi jenis kainnya, ukuran baju, kesepakatan harga dan terpenting adalah membayar uang muka.Dari kesepakatan akad itu tidak keluar dari ketentuan yang diajarkan syariah. Disisi lain ketika ada complain kondsumen dari pihak konveksi memberikan solusi dan saling menyepakati.

\section{KESIMPULAN}

Jual beli istishna' yaitu jual beli secara pesanan, dalam fikih sering disebut jual beli yang barangnya belum ada ataupun masih dalam proses. Rukun dan syarat jual beli as-salam yaitu Mu'aqidain yang meliputi Pembeli dan penjual, Obyek transaksi, Sighat 'ijab qabul, dan alat tukar.

Akad Istishna'yang diterapkan Duta Collection's sudah memenuhi syariat islam. Tahapan atau proses yang diterapkan Duta Collection's mulai pemesanan sampai barang jadi yakni Akad/pemesanan, pembayaran, pembuatan Mal/contoh potongan, pemotongan kain, mesin jahit, mesin obras, pengontrolan, mesin Itik dan terakhir proses finishing (setrika dan packing). Dan ketika ada complain dari konsumen pihak konveksi selalu memberikan solusi.

\section{DAFTAR PUSTAKA}

A. Karim , Adiwarman, 2007, Bank Islam; Analisis Fiqh Dan Keuangan, Eds. 3, Jakarta: PT. Raja Grafindo persada.

A. Mas'adi , Ghufron.2002, Fiqih Muamalah Kontektual, Jakarta : PT Raja Grafindo Persada.

Antonio, Muhammad Syafi'I. 2001. Bank Syariah Dari Teori ke Praktik. Jakarta: Gema Insani

Ascarya, 2013, Akad dan Produk Bank Syariah, RajawaliPers, Jakarta.

Chairuman Pasaribu; Suhrawardi K. Lubis S.H, Hukum Perjanjian Dalam Islam,(Jakarta : Sinar Grafika, 1994)

Dahlan, Abdul Aziz, 2003, Ensiklopedi Hukum Islam, Jakarta: PT. Ictiar Baru Van Hoeve. 
DEPAG. 2002. Al-Qur'an dan Terjemahnya. Surabaya

Hadi, Abd. 2010. Dasar-Dasar Hukum Ekonomi Islam. Surabaya : Putra Media Nusantara

Hamid , Abdul. Mahmud Al-Baeeali, Dawabit al-,,Uqud, Kairo: Maktabah Wahbah

Haroen, Nasrun, 2007, Fiqh Muamalah, Jakarta: Gaya Media Pratama

Husaini Mansur Dan Dhani Gunawan, 2007, Dimensi Perbankan Dalam AlQur'an, Jakarta:

Ismail. 2011. Perbankan syariah. Jakarta : Kencana

Nawawi , Ismail, 2012, Fiqih Muamalah Klasik dan Kontemporer,Bogor ;Ghalia Indonesia,2012.

Pasaribu, Chairuman; Suhrawardi K. Lubis, 1994. Hukum Perjanjian Dalam Islam. Jakarta : Sinar Grafika

PT. Visi Citah Kreasi.

Sabid, Sayid. 1998. Fikih Sunnah. Bandung : PT. Al Ma'arif

Syafei , Rachmat, 2001, Fiqih Mu'amalah, Bandung: CV. Pustaka Setia.

Wardi, Ahmad Muslich, 2010, Fiqh Muamalah, Jakarta : Amzah 
$150\}\{$ Implementasi Jual Beli Akad Istishna' Dikonveksi Duta Collection's 